\title{
Article \\ Disparities in Oral Nutritional Supplement Usage and Dispensing Patterns across Primary Care in Ireland: ONSPres Project
}

\author{
Aisling A. Geraghty 1,2 (D), Laura McBean 1,2, Sarah Browne 1,2 ${ }^{\mathbb{D}}$, Patricia Dominguez Castro ${ }^{1,2}$, \\ Ciara M. E. Reynolds 1,2, David Hanlon ${ }^{3}$, Gerard Bury ${ }^{4}$, Margaret O'Neill ${ }^{5}$, Sarah Clarke ${ }^{6}$, \\ Barbara Clyne ${ }^{7}$, Karen Finnigan ${ }^{8}$, Laura McCullagh ${ }^{8}$, Sharon Kennelly ${ }^{3}$ and Clare A. Corish ${ }^{1,2, * \mathbb{D}}$
}

Citation: Geraghty, A.A.; McBean, L.; Browne, S.; Dominguez Castro, P.

Reynolds, C.M.E.; Hanlon, D.; Bury, G.; O'Neill, M.; Clarke, S.; Clyne, B. et al. Disparities in Oral Nutritional Supplement Usage and Dispensing Patterns across Primary Care in Ireland: ONSPres Project. Nutrients 2022, 14, 338. https://doi.org/ $10.3390 /$ nu14020338

Academic Editors: Dariusz Nowak and Lidia Santarpia

Received: 3 December 2021

Accepted: 8 January 2022

Published: 14 January 2022

Publisher's Note: MDPI stays neutral with regard to jurisdictional claims in published maps and institutional affiliations.

Copyright: (C) 2022 by the authors. Licensee MDPI, Basel, Switzerland. This article is an open access article distributed under the terms and conditions of the Creative Commons Attribution (CC BY) license (https:// creativecommons.org/licenses/by/ $4.0 /)$.
1 School of Public Health, Physiotherapy and Sports Science, University College Dublin, Belfield, Dublin 4, Ireland; aisling.geraghty@ucdconnect.ie (A.A.G.); laura.mcbean@ucdconnect.ie (L.M.); sarah.browne1@ucd.ie (S.B.); domingup@tcd.ie (P.D.C.); cmereynolds2@gmail.com (C.M.E.R.)

2 UCD Institute of Food and Health, University College Dublin, Belfield, Dublin 4, Ireland

3 National HSE Primary Care Division, Service Improvement, Mountmellick Primary Care Building, Co. Laois, Ireland; david.hanlon1@hse.ie (D.H.); sharon.kennelly@hse.ie (S.K.)

4 School of Medicine, University College Dublin, Belfield, Dublin 4, Ireland; gerard.bury@ucd.ie

5 National HSE Health and Wellbeing Division, Dr. Steevens' Hospital, Dublin 8, Ireland; margaret.oneill1@hse.ie

6 HSE Medicines Management Programme, Department of Pharmacology and Therapeutics, Trinity Centre for Health Sciences, St. James's Hospital, Dublin 8, Ireland; saclarke@stjames.ie

7 HRB Centre for Primary Care Research, Department of General Practice, RSCI University of Medicine and Health Sciences, 123 St. Stephens Green, Dublin 2, Ireland; barbaraclyne@rcsi.ie

8 Department of Pharmacology and Therapeutics, Trinity Centre for Health Sciences, St. James's Hospital, Dublin 8, Ireland; karen.finnigan@tcd.ie (K.F.); lmccullagh@stjames.ie (L.M.)

* Correspondence: clare.corish@ucd.ie

\begin{abstract}
When treating malnutrition, oral nutritional supplements (ONSs) are advised when optimising the diet is insufficient; however, ONS usage and user characteristics have not been previously analysed. A retrospective secondary analysis was performed on dispensed pharmacy claim data for 14,282 anonymised adult patients in primary care in Ireland in 2018. Patient sex, age, residential status, ONS volume (units) and ONS cost (EUR) were analysed. The categories of 'Moderate' ( $<75$ th centile), 'High' (75th-89th centile) and 'Very High' ONS users ( $\geq 90$ th centile) were created. The analyses among groups utilised $t$-tests, Mann-Whitney $\mathrm{U}$ tests and chi-squared tests. This cohort was $58.2 \%$ female, median age was 76 years, with $18.7 \%$ in residential care. The most frequently dispensed ONS type was very-high-energy sip feeds (45\% of cohort). Younger males were dispensed more ONSs than females (<65 years: median units, 136 vs. 90; $p<0.01$ ). Patients living independently were dispensed half the volume of those in residential care (112 vs. 240 units; $p<0.01$ ). 'Moderate' ONS users were dispensed a yearly median of 84 ONS units (median cost, EUR 153), 'High' users were dispensed 420 units (EUR 806) and 'Very High' users 892 yearly units (EUR 2402; $p<0.01$ ). Further analyses should focus on elucidating the reasons for high ONS usage in residential care patients and younger males.
\end{abstract}

Keywords: malnutrition; oral nutritional supplements; primary care; older adults

\section{Introduction}

In Europe, $8.5 \%$ of older adults in the community and $17.5 \%$ in residential care are at high risk of malnutrition [1]. Approximately 140,000 adults in Ireland have disease-related malnutrition [2]. Enhancing dietary intake is the first approach for treatment of malnutrition and involves advice to consume foods that are high in energy and protein [3]. In circumstances where optimising the diet is not sufficient and malnutrition risk is high, oral nutritional supplements (ONSs) are advised. ONSs are products formulated to provide an 
energy- and protein-dense addition to an individual's habitual diet without the suppression of appetite or food intake [4]. ONSs are commercially manufactured and can be in liquid form, semi-solids, or powders, containing varying concentrations of macronutrients and micronutrients. Patients prescribed ONSs should be reviewed within three months to assess their clinical condition and monitor progress $[5,6]$. However, research in Ireland and the UK indicates that many patients prescribed ONSs do not undergo regular review [7-9].

General practitioners (GPs) are frequently the first contact point for communitydwelling individuals at risk of malnutrition and are the primary prescribers of ONSs in Ireland [10]. However, GPs often feel unsupported when managing malnutrition and report a lack of evidence-based decision making and confidence around ONSs [11]. In the UK, inconsistency and substantial differences in both the identification and management of malnutrition amongst adults in the community is also an issue [12]. ONS usage is influenced by an array of factors, such as variation in healthcare professionals' approaches, poor monitoring and inefficiencies as patients move between healthcare settings $[11,13,14]$. In the UK's National Health Service, dietitians can also prescribe ONSs, but prescribing is still influenced by various factors, including local policy and protocol, and patient circumstances [14].

Despite research focusing on determinants of malnutrition and methods of management [15], there remains a dearth of knowledge on patterns of ONS usage in the community and characteristics of ONS users. We aim to investigate the characteristics of patients in receipt of ONSs and describe patterns of ONS dispensing in a large population in Ireland in 2018.

\section{Materials and Methods}

\subsection{Study Design}

A retrospective secondary analysis was performed on anonymised dispensed pharmacy claim data in 2018 (from 1 January to 31 December inclusive). The data were obtained from the General Medical Services scheme (GMS), which provides free at the point-ofdelivery general practice care to around $30 \%$ of the Irish population with a defined lowincome threshold. A database was obtained which contained prescriptions dispensed through the GMS scheme, alongside demographic information for patients and prescribers (GPs). This information is managed by the Health Service Executive Primary Care and Eligibility Reimbursement Service (PCRS). The study examined all dispensed claims originating from GP practices located in three of Ireland's nine Community Health Organisations (in the counties of Dublin, Kildare and Wicklow in the Republic of Ireland) which comprise $30 \%$ of all dispensed pharmacy claims and 33\% of the GMS population nationally (approximately 300,000 people).

Data relating to all non-disease-specific ONSs, in addition to anonymised demographic information for 14,282 patients aged $\geq 18$ years and 700 GPs who had prescribed ONSs, were available for 2018. Data were only available for patients or GPs linked to a dispensed claim on the PCRS system. Ethical approval was obtained from the University College Dublin Human Research Ethics Committee (reference LS-18-50-Corish) and the Irish College of General Practitioners (ICGP) Research Ethics Committee.

The following data were analysed: patient sex, age, residential care status, ONS product and volume (in units) dispensed and cost of ONSs (EUR). The data were further grouped by age category (18-44, 45-64 and $\geq 65$ years, in line with previous research in this population [16]) and living situation (patient living in residential care or independently). Non-disease-specific ONSs were categorised by protein and energy content as described in Supplementary Table S1. Patients were categorised based on total volume (units) of ONSs dispensed into 'Moderate' ( $<75$ th centile of volume), 'High' (75th-89th centile) and 'Very High' ONS users ( $\geq 90$ th centile). This identified high users based on annual volumes dispensed over the course of the year and so may not have identified high clinical or daily usage over a shorter period within the year. Costs refer to the individual product cost calculated using publicly available standardised HSE-listed reimbursement price. 


\subsection{Statistical Analysis}

The assessment of normality for all variables was performed by visual analyses of histograms. Parametric or non-parametric tests were used as required. A bivariate analysis was used with one-sample $t$-tests to assess sex differences in the cohort. Mann-Whitney $\mathrm{U}$ tests were used to examine sex differences and differences between residential caredwelling and independent-dwelling patients in relation to age, ONS units and cost. Differences between age groups, intakes of ONS categories between groups and ONS user categories were investigated using cross-tabulations and the chi-squared statistical test. Results with a $p<0.05$ were considered significant. Statistical analyses were performed using SPSS (Statistical Package for the Social Sciences) software version 24.0 (IBM).

\section{Results}

\subsection{Characteristics of Patients on Oral Nutritional Supplements}

A total of 14,282 community-dwelling adults was dispensed ONSs (Table 1). The median age was 76 years with $71 \%$ of the cohort aged over 65 years. Females were older with a median age of 80 years, compared to 71 years in males $(p<0.001)$. In total, $81 \%$ of patients dispensed ONSs were living independently and $18.7 \%$ were in residential care $(p<0.001)$. A higher proportion of females in residential care were on ONSs than males $(23 \%$ vs. $12.6 \% ; p<0.001)$.

Table 1. Characteristics of patients dispensed oral nutritional supplements and their general practitioners over a 12-month period.

\begin{tabular}{|c|c|c|c|c|c|c|c|}
\hline & \multicolumn{2}{|c|}{ Total } & \multicolumn{2}{|c|}{ Male } & \multicolumn{2}{|c|}{ Female } & $p$ \\
\hline Patients $(n, \%)$ & 14,282 & 100 & 5946 & 41.6 & 8336 & 58.5 & $<0.001^{\mathrm{a}}$ \\
\hline Age (years, median, IQR) & 76.0 & 24.0 & 71.0 & 27.0 & 80.0 & 20.0 & $<0.001^{b}$ \\
\hline $18-44$ years $(n, \%)$ & 1500 & 10.5 & 784 & 13.2 & 716 & 8.6 & \\
\hline $45-64$ years $(n, \%)$ & 2592 & 18.2 & 1449 & 24.4 & 1143 & 13.7 & $<0.001^{\mathrm{c}}$ \\
\hline$\geq 65$ years $(n, \%)$ & 10,190 & 71.4 & 3713 & 62.5 & 6477 & 77.7 & \\
\hline \multicolumn{8}{|c|}{ Patient Care Location } \\
\hline Residential care $(n, \%)$ & 2674 & 18.7 & 750 & 12.6 & 1934 & 23.1 & \multirow{2}{*}{$<0.001^{c}$} \\
\hline Independent living $(n, \%)$ & 11,608 & 81.3 & 5196 & 87.4 & 6412 & 76.9 & \\
\hline \multicolumn{8}{|c|}{ General Practitioners $(n=700)$} \\
\hline \multicolumn{4}{|c|}{ Number of patients on ONSs (median, IQR) } & 13.5 & \multicolumn{3}{|c|}{22.0} \\
\hline \multicolumn{4}{|c|}{ Treating patients in residential care $(n, \%)$} & 273 & \multicolumn{3}{|c|}{39.0} \\
\hline \multicolumn{4}{|c|}{ Total ONS prescriptions † per GP (median, range) } & 20 & \multicolumn{3}{|c|}{$1-683$} \\
\hline \multicolumn{4}{|c|}{ Prescriptions † per patient (median, range) } & 1.43 & \multicolumn{3}{|c|}{$1-12$} \\
\hline
\end{tabular}

IQR, interquartile range; ONS, oral nutritional supplement. Non-parametric data are reported as median, IQR Statistical tests: ${ }^{a}$ One sample $t$-test, ${ }^{b}$ Mann-Whitney U test, ${ }^{c}$ chi-squared test. Statistical significance set at $p<0.05$. Data refer to non-disease-specific oral nutritional supplements dispensed between 1 January and 31 December 2018 inclusive. + Prescription related to one ONS product and irrespective of volume.

There were 1027 GPs on the GMS register within the healthcare areas analysed, $68.2 \%$ of whom were linked to a dispensed ONS claim $(n=700)$. Almost one-third $(31.8 \%, n=327)$ prescribed no ONS during 2018. Per GP, the median number of patients dispensed ONSs was 13; however, this ranged from 1 to 297 and almost $40 \%$ of GPs prescribed ONSs to a patient in residential care (Table 1).

\subsection{Characteristics of Oral Nutritional Supplement Dispensing}

A total of 3,640,446 units of ONSs were dispensed to this cohort in 2018. Per patient, this ranged from 1 to 7206 units, with a median of 126 units per patient (Table 2). Most patients $(92.5 \%)$ were dispensed under 730 units of ONSs, the equivalent of two units per day over the year. Overall, male patients were dispensed higher volumes of ONSs 
than females; however, when split by age, this was only seen in males aged $<65$ years (median, 136 units for males vs. 90 units for females; $p<0.001$ ). Specifically, males in the 18-44-year-old category were dispensed more units of ONSs than females in the same age category (median units, 120 (IQR 236) for males and 60 (IQR 146) for females; $p<0.01$ ).

Table 2. Characteristics of oral nutritional supplement usage over a 12-month period.

\begin{tabular}{|c|c|c|c|c|c|c|c|}
\hline & \multicolumn{2}{|c|}{ Total } & \multicolumn{2}{|c|}{ Males } & \multicolumn{2}{|c|}{ Females } & $p$ \\
\hline $\begin{array}{l}\text { Units of ONSs per patient (entire cohort) } \\
\text { (median, IQR) }\end{array}$ & 126.0 & 262.0 & 140.0 & 274.0 & 120.0 & 256.8 & $0.005^{b}$ \\
\hline Age group: 18-64 years (median, IQR) & 112.0 & 244.0 & 136.0 & 293.0 & 90.0 & 210.0 & $<0.001^{b}$ \\
\hline Age group: $\geq 65$ years (median, IQR) & 140.0 & 268.0 & 140.0 & 252.0 & 140.0 & 278.5 & $0.739^{b}$ \\
\hline \multicolumn{8}{|l|}{ ONS Costs (EUR) } \\
\hline $\begin{array}{c}\text { Cost of ONS per patient (entire cohort) } \\
\text { (median, IQR) }\end{array}$ & 251 & 585 & 265 & 604 & 246 & 580 & $0.007^{\mathrm{b}}$ \\
\hline Age group: 18-64 years (median, IQR) & 214 & 524 & 255 & 610 & 179 & 416 & $<0.001^{b}$ \\
\hline Age group: $\geq 65$ years (median, IQR) & 269 & 627 & 269 & 596 & 269 & 654 & $0.937^{b}$ \\
\hline ONS Category & \multicolumn{2}{|c|}{$\begin{array}{l}\text { Total Cohort } \\
n=14,282\end{array}$} & \multicolumn{2}{|c|}{$\begin{array}{c}\text { Patients } \\
\text { aged 18-64 years } \\
n=4092\end{array}$} & \multicolumn{2}{|c|}{$\begin{array}{c}\text { Patients } \\
\text { aged } \geq 65 \text { years } \\
n=10,190\end{array}$} & $p$ \\
\hline Very-high-energy sip feed $(n, \%)$ & 6459 & 45.2 & 1773 & 43.3 & 4686 & 46.0 & $0.004^{\mathrm{c}}$ \\
\hline High-energy, standard protein sip feed $(n, \%)$ & 4829 & 33.8 & 1813 & 44.3 & 3016 & 29.6 & $<0.001^{\mathrm{c}}$ \\
\hline High-energy modular $(n, \%)$ & 3393 & 23.8 & 617 & 15.1 & 2776 & 27.2 & $<0.001^{\mathrm{c}}$ \\
\hline High-protein sip feed $(n, \%)$ & 2473 & 17.3 & 611 & 14.9 & 1862 & 18.3 & $<0.001^{\mathrm{c}}$ \\
\hline High-energy semi-solid $(n, \%)$ & 2324 & 16.3 & 382 & 9.3 & 1942 & 19.1 & $<0.001^{\mathrm{c}}$ \\
\hline $\begin{array}{l}\text { Texture-modified high-energy, high-protein sip } \\
\text { feed }(n, \%)\end{array}$ & 168 & 1.2 & 10 & 0.2 & 158 & 1.6 & $<0.001^{\mathrm{c}}$ \\
\hline Other $(n, \%)$ & 1056 & 7.4 & 288 & 7.0 & 769 & 7.5 & $0.303^{c}$ \\
\hline
\end{tabular}

IQR, interquartile range; ONS, oral nutritional supplement. Non-parametric data are reported as median, IQR Statistical tests: ${ }^{\mathrm{b}}$ Mann-Whitney U test, ${ }^{\mathrm{c}}$ chi-squared test. Significance set at $p<0.05$. Data refer to non-diseasespecific oral nutritional supplements dispensed between 1 January and 31 December 2018 inclusive.

There were seven ONS categories, with the most common being very-high-energy sip feeds (which were dispensed to $45 \%$ of the cohort and making up $31.8 \%$ of all products (Table 2, Figure 1)). There was no difference in category of product dispensed to males and females, apart from high-energy semi-solid ONS products, which were more common for females $(18 \%$ vs. $13.8 \% ; p<0.001)$. However, when split by age, differences were observed (Table $2 ; p<0.001$ ).

\subsection{Oral Nutritional Supplement Dispensing in Residential Care Compared to Independent Living}

More patients within residential care were female (72\% vs. 55\% males) and aged $\geq 65$ years $(99 \%$ of females vs. $65 \%$ of males; $p<0.001$ ) than patients living independently (Table 3). Residential care patients had higher volumes of ONS dispensed (median, 240 units vs. 112; $p<0.001$ ) and ONSs were also more costly, with the median yearly cost being EUR 541, compared to EUR 212 for patients living independently $(p<0.001)$. Dispensing patterns of all ONS categories differed based on residential status (Table 3). The ONS products dispensed in each category split by residential status are presented in Figure 2. 


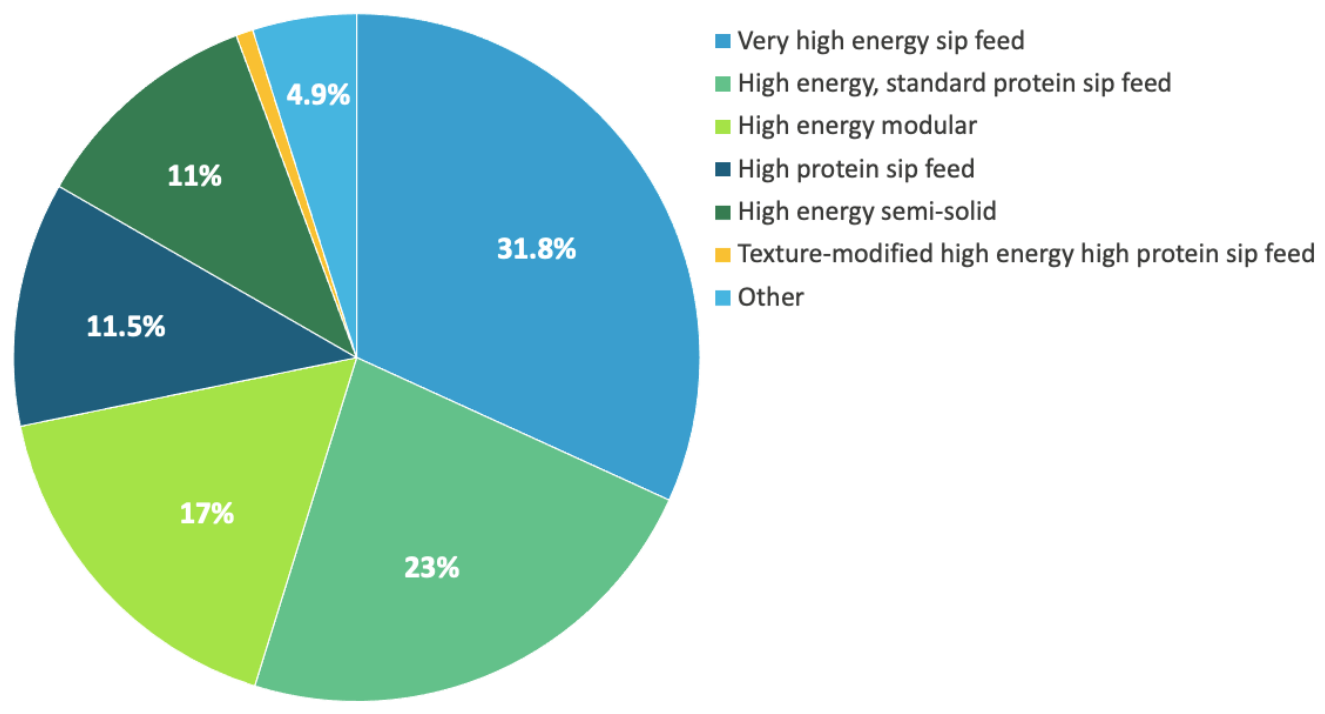

Figure 1. Breakdown of oral nutritional supplement products dispensed across categories in the full cohort $(n=14,282)$.

Table 3. Comparison of characteristics and oral nutritional supplement dispensing between patients living in residential care and living independently across a 12-month period.

\begin{tabular}{|c|c|c|c|c|c|}
\hline \multirow[b]{2}{*}{ Total $(n, \%)$} & \multicolumn{2}{|c|}{ Residential Care } & \multicolumn{2}{|c|}{ Independent-Living } & \multirow[t]{2}{*}{$p$} \\
\hline & 2674 & 18.7 & 11,608 & 81.3 & \\
\hline Female $(n, \%)$ & 1924 & 72.0 & 6412 & 55.2 & $<0.001^{\mathrm{a}}$ \\
\hline Age (years, median, IQR) & 86.0 & 10.0 & 73.0 & 25.0 & $<0.001^{b}$ \\
\hline $18-44$ years $(n, \%)$ & 4 & 0.1 & 1496 & 12.9 & \\
\hline $45-64$ years $(n, \%)$ & 15 & 0.6 & 2577 & 22.2 & $<0.001^{a}$ \\
\hline$\geq 65$ years $(n, \%)$ & 2655 & 99.3 & 7535 & 64.9 & \\
\hline \multicolumn{6}{|c|}{ ONS } \\
\hline Units per patient (median, IQR) & 240 & 436 & 112 & 224 & $<0.001^{b}$ \\
\hline Cost per patient (EUR, median, IQR) & 541 & 1398 & 212 & 479 & $<0.001^{b}$ \\
\hline \multicolumn{6}{|c|}{ ONS Category } \\
\hline Very-high-energy sip feed $(n, \%)$ & 1290 & 48.2 & 5169 & 44.5 & $0.001^{\mathrm{a}}$ \\
\hline $\begin{array}{c}\text { High-energy, standard protein sip } \\
\text { feed }(n, \%)\end{array}$ & 513 & 19.2 & 4316 & 37.2 & $<0.001^{a}$ \\
\hline High-energy modular $(n, \%)$ & 1194 & 44.7 & 2199 & 18.9 & $<0.001^{\mathrm{a}}$ \\
\hline High-protein sip feed $(n, \%)$ & 603 & 22.6 & 1870 & 16.1 & $<0.001^{\mathrm{a}}$ \\
\hline High-energy semi-solid $(n, \%)$ & 938 & 35.1 & 1386 & 11.9 & $<0.001^{\mathrm{a}}$ \\
\hline $\begin{array}{l}\text { Texture-modified high-energy, } \\
\text { high-protein sip feed }(n, \%)\end{array}$ & 105 & 3.9 & 63 & 0.5 & $<0.001^{a}$ \\
\hline Other $(n, \%)$ & 235 & 8.8 & 821 & 7.1 & $0.002^{\mathrm{a}}$ \\
\hline
\end{tabular}

$\overline{\mathrm{IQR}}$, interquartile range; ONS, oral nutritional supplement. Non-parametric data are reported as median, IQR Statistical tests: ${ }^{a}$ chi-squared test, ${ }^{b}$ Mann-Whitney U test. Significance set at $p<0.05$. Data refer to non-diseasespecific oral nutritional supplements dispensed between 1 January and 31 December 2018 inclusive.

\subsection{Characteristics of 'High' and 'Very High' Oral Nutritional Supplement Users}

There were 2152 patients (15.1\%) classified as 'High' ONS users and $1428(10 \%)$ 'Very high' ONS users (Table 4). The median age of those in the 'High' and 'Very High' user categories was higher than that of 'Moderate' ONS users $(p<0.001)$. There were more females in each group; however, the proportion of males increased in the 'High' and 'Very High' users groups $(p=0.04)$. 


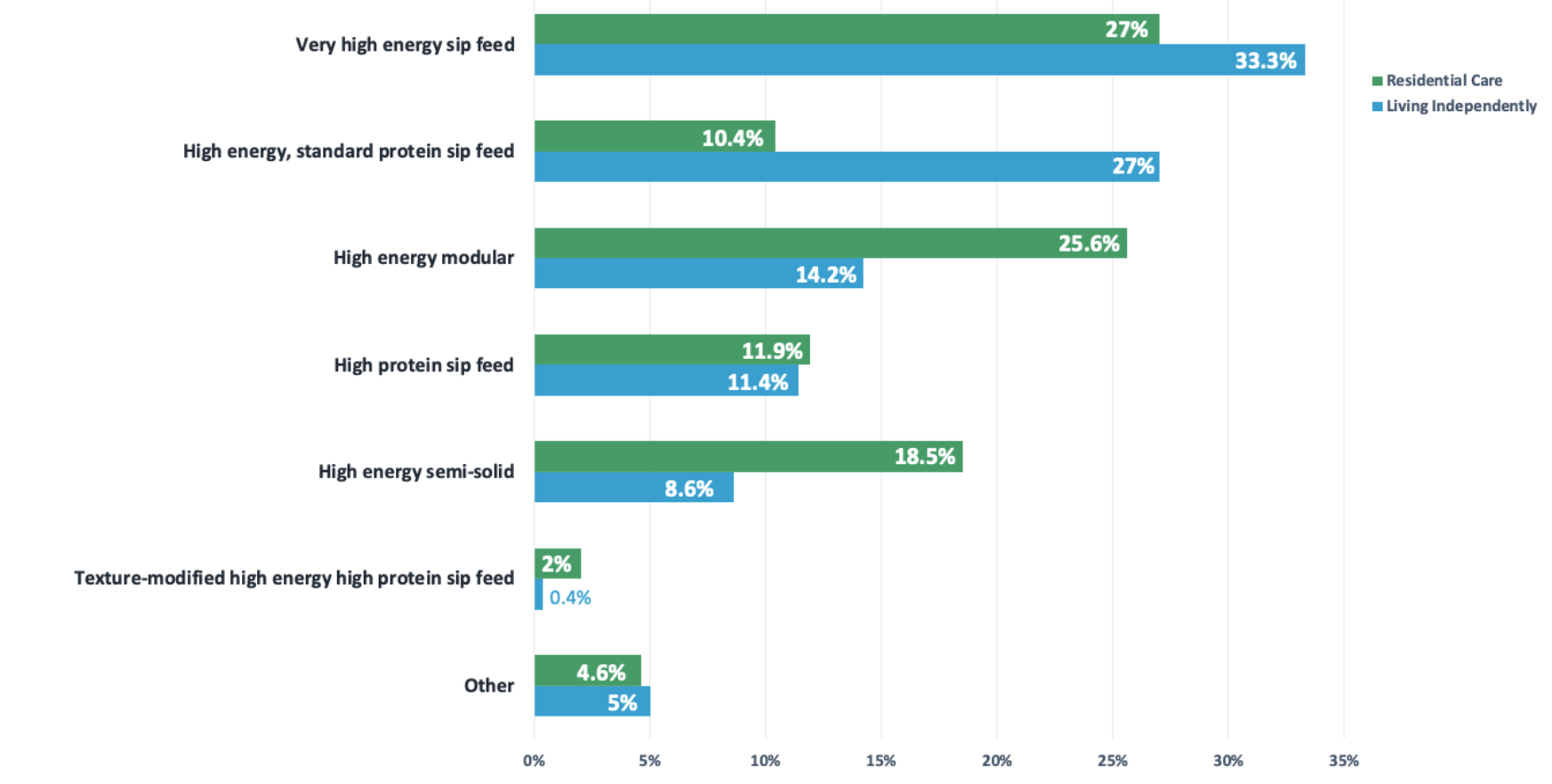

Figure 2. Bar chart with breakdown of all oral nutritional supplement products dispensed in the cohort from each category to patients in residential care and patients living independently.

Table 4. Characteristics of 'Moderate', 'High' and 'Very High' volume oral nutritional supplement usage in cohort over a 12 -month period.

\begin{tabular}{|c|c|c|c|c|c|c|c|}
\hline \multirow[b]{2}{*}{ Patients $(n, \%)$} & \multicolumn{2}{|c|}{$\begin{array}{c}\text { ‘Moderate' ONS Users } \\
\quad \text { (<75th Centile) }\end{array}$} & \multicolumn{2}{|c|}{$\begin{array}{l}\text { 'High' ONS Users } \\
\text { (75th-89th Centile) }\end{array}$} & \multicolumn{2}{|c|}{$\begin{array}{l}\text { ‘Very High' ONS Users } \\
\text { ( } \geq 90 \text { th Centile })\end{array}$} & \multirow[t]{2}{*}{$p$} \\
\hline & 10,702 & 74.9 & 2152 & 15.1 & 1428 & 10 & \\
\hline Male $(n, \%)$ & 4425 & 41.3 & 909 & 42.2 & 612 & 42.9 & \multirow{2}{*}{$0.040^{a}$} \\
\hline Female $(n, \%)$ & 6277 & 58.7 & 1243 & 57.8 & 816 & 57.1 & \\
\hline Age (years, median, IQR) & 76 & 24 & 78 & 24 & 77 & 25 & \multirow[t]{2}{*}{$<0.001^{b}$} \\
\hline $18-44$ years $(n, \%)$ & 1160 & 10.8 & 197 & 9.2 & 143 & 10.0 & \\
\hline $45-64$ years $(n, \%)$ & 1942 & 18.1 & 378 & 17.6 & 272 & 19.0 & \multirow[t]{2}{*}{$0.022^{\mathrm{a}}$} \\
\hline$\geq 65$ years $(n, \%)$ & 7600 & 71.0 & 1577 & 73.3 & 1013 & 70.9 & \\
\hline \multicolumn{8}{|c|}{ Patient Care Location } \\
\hline Residential care $(n, \%)$ & 1581 & 14.8 & 573 & 26.6 & 520 & 36.4 & \multirow[b]{2}{*}{$0.001^{a}$} \\
\hline Independent living $(n, \%)$ & 9121 & 85.2 & 1579 & 73.4 & 908 & 63.6 & \\
\hline \multicolumn{8}{|c|}{ ONS } \\
\hline Units per patient (median, IQR) & 84 & 127 & 420 & 146 & 892 & 476 & $<0.001^{b}$ \\
\hline Cost per patient (EUR, median, IQR) & 153 & 240 & 806 & 490 & 2402 & 6347 & $<0.001^{b}$ \\
\hline
\end{tabular}

$\mathrm{IQR}$, Interquartile range; ONS, oral nutritional supplement. Non-parametric data are reported as median, IQR Statistical tests: ${ }^{\mathrm{a}}$ chi-squared test, ${ }^{\mathrm{b}}$ Mann-Whitney U test Significance set at $p<0.05$. Data refer to non-diseasespecific oral nutritional supplements dispensed between 1 January and 31 December 2018 inclusive.

Of 'Very High' and 'High' users, $36.4 \%$ and $26.6 \%$ were in residential care, respectively, compared to only $14.8 \%$ of 'Moderate' users $(p<0.001)$. 'Moderate' ONS users had a median 84 units yearly of ONS dispensed (median costs of EUR 153 per patient), 'High' ONS users 420 units (EUR 806) and 'Very High' ONS users had 892 units (EUR 2402; $p<0.001$ ).

\section{Discussion}

\subsection{Main Findings}

In this analysis of 14,282 patients aged over 18 years, clear disparities were identified in ONS usage across patient age groups, between males and females and also between 
patients living independently in the community and patients in residential care facilities. In particular, higher ONS usage was noted in younger males and among patients in residential care, with further differences in ONS category usage identified among patients in residential care. In this sample of one third of Ireland's population, two-thirds of GPs had prescribed ONSs at least once during the year, with medians of 20 prescriptions for 13.5 patients, identifying this role as an important issue for general practice.

\subsection{Comparison with Existing Literature}

We identified a higher proportion of female patients on ONSs, similar to previous research in Ireland and internationally reporting ONS users being predominantly female and older [1,8]. This may be due to females having higher life expectancies and, as a result, increased frailty and risk of malnutrition. Although more ONS users were female, younger males were dispensed much higher volumes. We found males aged under 44 were dispensed twice the volume of ONSs compared to females, beyond what could be explained by their increased nutritional requirements or treatment of conditions such as Crohn's Disease. Research carried out in America similarly found that the proportion of males was higher among ONS users in a slightly younger population [17].

This raises the question around the use of ONSs in younger populations and factors influencing their prescription. Our group has previously described an association between ONS prescribing in this age group and simultaneous prescribing of psychoactive drugs [16]; chronic illness and multimorbidity are common among opiate-dependent patients in Ireland [18]. ONS prescribing may be a feature of the management of opiate dependency in Ireland and further research should explore the implications of this finding. Recent qualitative research exploring factors influencing ONS prescribing focused mainly on older adults and found that ONSs were often prescribed without evidence for their use [11,13]. Additional enquiry is needed to understand these patterns and whether they are related to social factors.

Despite the reported effectiveness of ONSs in managing malnutrition in patients in residential care [19], we found that these patients were dispensed twice the volume of ONSs compared to patients living independently. Research carried out on 23,500 patients in residential care across Europe and America found that almost 14\% used ONSs and usage was associated with increasing age and functional impairment [20]. Similarly, in this population, polypharmacy was associated with long-term usage of ONSs, which may indicate a decline in health [16]. Although higher requirements for ONSs in residential care may be explained by the advancing age of patients, which is also reflected by the higher proportions of female patients who have a longer life expectancy and higher disease rates, given that they have access to and assistance with meals and snacks in residential care, this increased need should be mitigated. Unfortunately, data on medication or health status were not available in this analysis, but future analyses should incorporate these to help elucidate the reasons behind increased ONS use in residential care.

While dietary counselling combined with ONSs in care homes have been shown to be highly effective for treating malnutrition [21], the appropriateness of ONS prescribing in this setting remains a concern. Reported ONS usage in residential care varies drastically with a recent publication estimating rates ranging from $1 \%$ to $43 \%$ across countries [20]. Previous research in Ireland indicated that up to one-third of ONS prescriptions in the community were inappropriate for patient needs [8] and a recent review of ONS usage within care homes in the UK identified high levels of inappropriate prescribing [7]. Similarly, a recent analysis in the United States reported that, although $25 \%$ of their cohort of adults in the community were classified as being at high risk of malnutrition, only $11 \%$ consumed ONSs [17]. This highlights the need for clarification around appropriate prescribing of ONSs, particularly for patients in residential care due to the variations in usage in this setting.

There is limited research on factors influencing prescriber choice of ONS products. However, recent research in Ireland similarly identified a preference for high-protein 
ONS products with the main factors driving ONS product choice being nutritional value and patient palatability [22]. We found that the ONS category did not differ between males and females; however, patient age and residential location did differ with the ONS category dispensed. Previously, in Ireland, the cost of ONSs was reported as a concern for ONS prescribers [11], which may influence the product prescribed. We found that almost one-third of GPs within these community areas did not prescribe ONSs for any patients, potentially also due to cost concerns and lack of standardised screening for malnutrition. This is despite evidence from a recent systematic review indicating that ONS use in the community is near neutral or produces a cost advantage [23]. This, alongside differences in ONS products and volumes, suggests that education and support are needed for GPs and healthcare professionals prescribing ONSs.

\subsection{Strengths and Limitations}

This analysis had many strengths, in that it included comprehensive prescribing data for around 300,000 people (30\% of the GMS population in Ireland) and identified almost 15,000 ONS users. As the data related to dispensed ONS claims, this removed any reporting or recall bias from patients or healthcare providers relating to ONS usage. However, this analysis was not without limitations. Only data relating to patients or GPs linked to a dispensed ONS claim on the PCRS system were available, so comparisons between nonONS using patients or non-ONS prescribing GPs were not possible. Limited characteristics and demographic information were available on patients and the background of the users, including the purpose of dispensing, is not known, so future analysis should explore the impact of factors such as socioeconomic status, health status and other medication usage. Additional avenues of exploration which could help elucidate these findings include prevalent pathologies, the degree of malnutrition and ONS effectiveness. As these data related to ONS dispensing claims rather than consumption of ONSs, it was not possible to access appropriate ONS usage and, similarly, prescribing practises could not be evaluated without a review of individual patients, which is highly encouraged in future studies.

\subsection{Implications for Research and Practice}

Particular consideration should be given to younger males and patients in residential care facilities which used higher volumes of ONSs. Of equal concern is the possible 'under-treatment' of malnutrition by GPs. Given that 30\% of GPs did not prescribe any ONSs, there is a need for consistent approaches whereby evidence-based prescribing is implemented in all settings. Further education around appropriate usage of ONSs, both for patients and healthcare professionals, is vital to ensure both appropriate prescribing and appropriate usage of ONSs, to efficiently prevent and treat malnutrition in the community. Multidisciplinary teams are indispensable in effectively managing malnutrition in our community and adequate support must be provided at all levels of healthcare to ensure successful treatments.

\section{Conclusions}

Strong disparities were identified in ONS usage between patient groups in primary care in Ireland. Further research is warranted to elucidate the reasons for high ONS usage in younger males and patients in residential care. Further education and support are required for healthcare professionals working in malnutrition management.

Supplementary Materials: The following supporting information can be downloaded at: https: / / www.mdpi.com/article/10.3390/nu14020338/s1, Table S1: Category and nutritional content of oral nutritional supplements. 


\begin{abstract}
Author Contributions: Conceptualization, C.A.C., P.D.C. and C.M.E.R.; methodology, C.A.C., P.D.C and C.M.E.R.; formal analysis, A.A.G. and L.M.; investigation, A.A.G., L.M., S.K. and C.A.C.; data curation, P.D.C., C.M.E.R. and S.K.; writing—original draft preparation, A.A.G.; supervision, A.A.G., S.K. and C.A.C.; writing-review and editing, all authors; funding acquisition, C.A.C. All authors have read and agreed to the published version of the manuscript.
\end{abstract}

Funding: This work was supported by the Irish Health Research Board (HRB) under a quality and patient safety funding stream (RCQPS-2017-4).

Institutional Review Board Statement: The study was conducted according to the guidelines of the Declaration of Helsinki and approved by the Irish College of General Practitioners (ICGP) Research Ethics Committee and the University College Dublin Human Research Ethics Committee (reference LS-18-50-Corish).

Informed Consent Statement: Not applicable, as this was a retrospective secondary analysis on anonymised dispensed pharmacy claim data.

Data Availability Statement: Data available upon reasonable request to the corresponding author.

Acknowledgments: The authors would like to thank the collaborators and co-applicants on the ONSPres project for their input into this research project, particularly Celine Murrin, Carla Perrotta and Eileen Gibney and the following from the PCRS for providing and their guidance with the data: Kate Mulvenna, Linda Fitzharris, and Anne Marie Bennett. The authors would also like to acknowledge the HRB for funding this project under a quality and patient safety funding stream (RCQPS-2017-4). The HRB aims to ensure that new knowledge is created and then used in policy and practice. In doing this, the HRB supports health system innovation and creates new enterprise opportunities.

Conflicts of Interest: The authors declare no conflict of interest. The funders had no role in the design of the study; in the collection, analyses, or interpretation of data; in the writing of the manuscript, or in the decision to publish the results.

\title{
References
}

1. Leij-Halfwerk, S.; Verwijs, M.H.; van Houdt, S.; Borkent, J.W.; Guaitoli, P.R.; Pelgrim, T.; Heymans, M.W.; Power, L.; Visser, M.; Corish, C.A.; et al. Prevalence of protein-energy malnutrition risk in European older adults in community, residential and hospital settings, according to 22 malnutrition screening tools validated for use in adults $\geq 65$ years: A systematic review and meta-analysis. Maturitas 2019, 126, 80-89. [CrossRef] [PubMed]

2. Rice, N.; Normand, C. The cost associated with disease-related malnutrition in Ireland. Public Health Nutr. 2012, 15, 1966-1972. [CrossRef] [PubMed]

3. Dera, M.; Woodham, D. Treating malnutrition in the community. Br. J. Community Nurs. 2016, 21, 558-562. [CrossRef] [PubMed]

4. Stratton, R.; Smith, T.; Gabe, S. Managing Malnutrition to Improve Lives and Save Money; BAPEN British Association of Parenteral and Enteral Nutrition: Redditch, UK, 2018.

5. Health Service Executive. Prescribing Pathway for the Initiation and Renewal of Standard Oral Nutritional Supplements (ONS) for Adults Living in the Community; HSE: Dublin, Ireland, 2019.

6. Cadogan, C.A.; Dharamshi, R.; Fitzgerald, S.; Corish, C.A.; Dominguez Castro, P.; Ryan, C. A systematic scoping review of interventions to improve appropriate prescribing of oral nutritional supplements in primary care. Clin. Nutr. 2019, 39, 654-663. [CrossRef] [PubMed]

7. Collins, C.; Tucker, C.; Walton, C.; Podbur, S.; Barrett, S. Pharmacy Technician Review of Oral Nutritional Supplements (ONS) within Care Homes. Pharmacy 2019, 7, 28. [CrossRef] [PubMed]

8. Kennelly, S.; Kennedy, N.P.; Rughoobur, G.F.; Slattery, C.G.; Sugrue, S. The use of oral nutritional supplements in an Irish community setting. J. Hum. Nutr. Diet. 2009, 22, 511-520. [CrossRef] [PubMed]

9. Gall, M.J.; Harmer, J.E.; Wanstall, H.J. Prescribing of oral nutritional supplements in Primary Care: Can guidelines supported by education improve prescribing practice? Clin. Nutr. 2001, 20, 511-515. [CrossRef] [PubMed]

10. Loane, D.; Flanagan, G.; Siún, A.; McNamara, E.; Kenny, S. Nutrition in the community-an exploratory study of oral nutritional supplements in a health board area in Ireland. J. Hum. Nutr. Diet. 2004, 17, 257-266. [CrossRef] [PubMed]

11. Dominguez Castro, P.; Reynolds, C.M.E.; Kennelly, S.; Clyne, B.; Bury, G.; Hanlon, D.; Murrin, C.; McCullagh, L.; Finnigan, K.; Clarke, S.; et al. General practitioners' views on malnutrition management and oral nutritional supplementation prescription in the community: A qualitative study. Clin. Nutr ESPEN 2020, 36, 116-127. [CrossRef] [PubMed]

12. Allmark, G.; Calder, P.C.; Marino, L.V. Research identified variation in nutrition practice by community prescribing dietitians with regards to the identification and management of malnutrition amongst community dwelling adults. Nutr. Res. 2020, 76, 94-105. [CrossRef] [PubMed] 
13. Browne, S.; Kelly, L.; Geraghty, A.G.; Reynolds, C.M.; McBean, L.; McCallum, K.; Clyne, B.; Bury, G.; Perrotta, C.; Kennelly, S.; et al. Healthcare professionals' perceptions of malnutrition management and oral nutritional supplement prescribing in the community: A qualitative study. Clin. Nutr. ESPEN, 2021; in press.

14. Gibbs, M.; Drey, N.; Baldwin, C. Oral nutrition support interventions for patients who are malnourished or at risk of malnutrition: A survey of clinical practice amongst UK dietitians. J. Hum. Nutr. Diet. 2019, 32, 108-118. [CrossRef]

15. O'Keeffe, M.; Kelly, M.; O’Herlihy, E.; O’Toole, P.W.; Kearney, P.M.; Timmons, S.; O'Shea, E.; Stanton, C.; Hickson, M.; Rolland, Y.; et al. MaNuEL consortium. Potentially modifiable determinants of malnutrition in older adults: A systematic review. Clin. Nutr. 2019, 38, 2477-2498. [CrossRef]

16. Dominguez Castro, P.; Reynolds, C.; Bizzaro, M.G.; Kennelly, S.; Clyne, B.; Bury, G.; Bradley, C.; Finnigan, K.; McCullagh, L.; Murrin, C.; et al. Characteristics and determinants of high volume dispensing in long-term oral nutritional supplement users in primary care: A secondary analysis. BJGP Open 2021, 5. [CrossRef]

17. Sulo, S.; Schiffer, L.; Sheean, P.; Farrar, I.; Partridge, J.; Fitzgibbon, M. Community-Dwelling Adults at Nutrition Risk: Characteristics in Relation to the Consumption of Oral Nutritional Supplements. J. Prim. Care Community Health 2020, 11. [CrossRef]

18. Cullen, W.; O’Brien, S.; O'Carroll, A.; O'Kelly, F.D.; Bury, G. Chronic illness and multimorbidity among problem drug users: A comparative cross sectional pilot study in primary care. BMC Fam. Pract. 2009, 10, 25. [CrossRef] [PubMed]

19. Parsons, E.L.; Stratton, R.J.; Cawood, A.L.; Smith, T.R.; Elia, M. Oral nutritional supplements in a randomised trial are more effective than dietary advice at improving quality of life in malnourished care home residents. Clin. Nutr. 2017, 36, 134-142. [CrossRef] [PubMed]

20. Streicher, M.; Themessl-Huber, M.; Schindler, K.; Sieber, C.C.; Hiesmayr, M.; Volkert, D. Who receives oral nutritional supplements in nursing homes? Results from the nutritionDay project. Clin. Nutr. 2017, 36, 1360-1371. [CrossRef]

21. Reinders, I.; Volkert, D.; de Groot, L.C.; Beck, A.M.; Feldblum, I.; Jobse, I.; Neelemaat, F.; de van der Schueren, M.A.E.; Shahar, D.R.; Smeets, E.T.H.C.; et al. Effectiveness of nutritional interventions in older adults at risk of malnutrition across different health care settings: Pooled analyses of individual participant data from nine randomized controlled trials. Clin. Nutr. 2019, 38, 1797-1806. [CrossRef]

22. Uí Dhuibhir, P.; Collura, N.; Walsh, D. Complete Oral Nutritional Supplements: Dietitian Preferences and Clinical Practice. J. Diet. Suppl. 2019, 16, 40-50. [CrossRef]

23. Elia, M.; Normand, C.; Laviano, A.; Norman, K. A systematic review of the cost and cost effectiveness of using standard oral nutritional supplements in community and care home settings. Clin. Nutr. 2016, 35, 125-137. [CrossRef] 